\title{
Use of Bromocriptine for the Treatment of Peripartum Cardiomy- opathy: A Meta-Analysis of Randomized Controlled Trials
}

\section{Danielle Louis E Villanueva ${ }^{1^{*}}, M D$, Lauren Kay Evangelista ${ }^{1}, M D$, Ma Cristina Espanillo-Villanueva, $M D^{2}$ and John C Anonuevo, $M D^{1}$}

\author{
${ }^{1}$ Division of Cardiovascular Medicine, Philippine General Hospital, University of the Philippines, Philippines \\ ${ }^{2}$ Section of Maternal and Fetal Medicine, Department of Obstetrics and Gynecology, Philippine General \\ Hospital, University of the Philippines, Philippines
}

*Corresponding author: Danielle Louis Villanueva, MD, Division of Cardiovascular Medicine, Philippine General Hospital, University of the Philippines, Taft Avenue, Manila Philippines, Postal Code: 1000, Philippines, Tel: +63-922-825-8739

\begin{abstract}
Background: Peripartum cardiomyopathy is a rare, pregnancy associated cause of left ventricular heart failure in previously healthy women. It remains an important cause of cardiac-related maternal morbidity and mortality worldwide. Half of the patients will recover left ventricular function after 6 months. However, in the remainder of patients who do not recover cardiac function, they will require advanced heart failure therapies. Bromocriptine, a dopamine agonist which inhibits prolactin release, has demonstrated improvement in left ventricular recovery and clinical outcome. We sought to determine the effect of adding Bromocriptine to standard heart failure therapy on the improvement and recovery of left ventricular function and cardiovascular mortality of these patients.
\end{abstract}

Inclusion criteria: Studies were included if they satisfied the following criteria: 1) Randomized Controlled Trials; 2) Pregnant patients who fulfilled the criteria for diagnosis of peripartum cardiomyopathy and 3) Reported data on improvement in left ventricular ejection fraction and clinical outcomes.

Methods: Using PUBMED, Clinical Key, Science Direct, Scopus, and Cochrane databases, a search for eligible studies was conducted from June to December 31, 2018. The quality of each study was evaluated using the Cochrane Risk of Bias Tool. The primary outcome of interest is on the effect of Bromocriptine on the improvement of left ventricular function and clinical outcomes among these patients. Review Manager 5.3 was utilized to perform analysis of random effects for continuous outcomes.
Results: We identified 2 randomized controlled trials of 116 pregnant patients diagnosed with peripartum cardiomyopathy, showing that among those who received Bromocriptine on top of standard heart failure therapy, there is a significant improvement in the left ventricular ejection fraction at 6 months [mean difference $15.14(95 \% \mathrm{Cl}, 6.53$ to 23.75$) \mathrm{p}$ $<0.05$ ] compared to standard heart failure therapy alone. It was also observed that those who received Bromocriptine had better clinical outcomes.

Conclusion: The addition of Bromocriptine on top of standard heart failure therapy significantly improved the left ventricular ejection fraction of patients with peripartum cardiomyopathy at 6-months post-partum. This novel therapy may be considered to improve the management of these patients.

\section{Keywords}

Bromocriptine, Peripartum cardiomyopathy, PPCM

\section{Background of the Study}

Peripartum cardiomyopathy (PPCM) is characterized by a new onset of acute heart failure occurring among previously healthy pregnant patients between 1 month before and up to 5 months after delivery [1] . Peripartum cardiomyopathy has recently been recognized as an important cause of morbidity and mortality among patients with pregnancy induced heart failure [2-3]. Among those surviving, $23-54 \%$ of these patients showed recovery of cardiac function after 6 months [4] but some will require advanced heart

Citation: Villanueva DLE, Evangelista LK, Espanillo-Villanueva MC, Anonuevo JC (2020) Use of Bromocriptine for the Treatment of Peripartum Cardiomyopathy: A Meta-Analysis of Randomized Controlled Trials. Int J Clin Cardiol 7:171. doi.org/10.23937/2378-2951/1410171

Accepted: April 08, 2020; Published: April 10, 2020

Copyright: (C) 2020 Villanueva DLE, et al. This is an open-access article distributed under the terms of the Creative Commons Attribution License, which permits unrestricted use, distribution, and reproduction in any medium, provided the original author and source are credited. 
failure therapies such as ventricular assist device and heart transplantation [5].

General risk factors identified are hypertension, diabetes, obesity, smoking and substance abuse, African ancestry, and malnutrition. While possible pregnancy related risk factors are pre-eclampsia, cesarean section, multi-parity, twin pregnancy, teenage pregnancy, advanced maternal age, and prolonged tocolytic therapy $[3,6]$. In a German registry of 170 patients with peripartum cardiomyopathy from 2006-2011, majority of patients underwent cesarean section, has pre-eclampsia, and were obese [7].

Presently, the recommendation is to manage it similar to the guideline directed management of heart failure with reduced ejection fraction. Furthermore, with early recognition, diagnosis, and treatment, most of the patients recover. However, for those who do not recover their cardiac function, heart failure therapy becomes lifelong and indefinite. This led to further research on the management of PPCM.

Since the pathophysiology of peripartum cardiomyopathy has not been well established, a number of contributory factors has been recognized [2]. A pro-inflammatory response was demonstrated in a large cohort of PPCM patients as evidenced by elevated plasma levels of tumor necrosis factor, Fas-Apo-1, interleukin-6, and C-reactive protein [8]. One important discovery is the role of the nursing hormone prolactin and the production of its cleaved $16 \mathrm{kDa} \mathrm{N}$-terminal fragment in the pathophysiology of PPCM. Recent experimental studies have suggested that high levels of $16 \mathrm{kDA}$ prolactin during pregnancy initiates inflammation and endothelial damage which may lead to cardiomyocyte dysfunction and subsequently cardiomyopathy while the inhibition of the production of prolactin by Dopamine D2 receptor stimulation prevents the onset of cardiomyopathy [9-12]. With this concept, there have been studies on decreasing the production of prolactin by preventing its release by stimulating the dopamine D2 receptor. This has led to the hypothesis on the possibility of Bromocriptine, a well known dopamine agonist used to stop breastfeeding in post-partum women, to be used in the prevention of PPCM.

Several case reports have observed the beneficial effects of adding Bromocriptine to standard heart failure therapy in patients with acute PPCM $[10,13,14]$. Experimental Studies have also been done on Bromocriptine's possible use for peripartum cardiomyopathy based on its mechanism of action of decreasing prolactin production [9-12]. In addition, cytoprotective effects of Bromocriptine were also shown in various organs besides the heart [15]. With these promising results, a pilot study by Sliwa, et al. in 2010 [16] was done where they showed that patients with PPCM who were treated with Bromocriptine on top of standard heart failure therapy displayed great- er recovery of left ventricular ejection fraction $(27 \%$ to $58 \%$; P 0.012 ) compared with PPCM patients $(27 \%$ to $36 \%$ ) treated with standard heart failure therapy alone at 6 months. It was also observed that there were more deaths in the standard heart failure therapy group compared to the Bromocriptine treated group. In addition, significantly fewer patients experienced the composite end point of poor outcome defined as death, New York Heart Association functional class III/IV, or left ventricular ejection fraction $35 \%$ at 6 months in the Bromocriptine treated group. This study showed promising results however they only included 20 PPCM patients and their results cannot be considered definitive. A subsequent randomized controlled trial was done in 2012 by Yameogo, et al. [17] which included 96 women with PPCM. Similarly, at six months, echocardiographic findings demonstrated significantly better improvement of LVEF in the Bromocriptine treated group than the standard heart failure therapy group (Mean LVEF at 6 months: $49 \%$ vs. $40 \%$ ). This improvement in LVEF was further seen at 12 months where the LVEF improved to 54\% in the Bromocriptine treated group. Further studies were done on Bromocriptine's role in PPCM. A prospective cohort study of 115 patients in Germany by Haghikia, et al. [7] also showed that the mean follow-up LVEF at 6 months were $27 \pm 9$ to $47 \pm 19 \%$ in the Bromocriptine treated group. In addition, majority of the Bromocriptine treated patients showed improvement in functional class. These results were also observed by Marquis-Gravel, et al. [18] in 2015.

The improvement of cardiac function in these studies may suggest the possible role of Bromocriptine as an add-on to standard heart failure therapy in terms of improvement in mean LVEF at 6 months as well as improvement in clinical outcomes of PPCM patients. We therefore aim to synthesize the available evidence to determine the effect of adding Bromocriptine to standard heart failure therapy among patients with pregnancy induced cardiomyopathy or peripartum cardiomyopathy.

\section{Research Question}

Among adult pregnant patients who develop peripartum cardiomyopathy, what is the effect of Bromocriptine in addition to guideline directed heart failure therapy on the improvement of left ventricular function and cardiovascular mortality?

\section{Objectives}

- To determine the effect of adding Bromocriptine to guideline directed heart failure therapy on the improvement of left ventricular ejection fraction among adult pregnant patients with peripartum cardiomyopathy.

- To determine the effect of adding Bromocriptine to guideline directed heart failure therapy on car- 


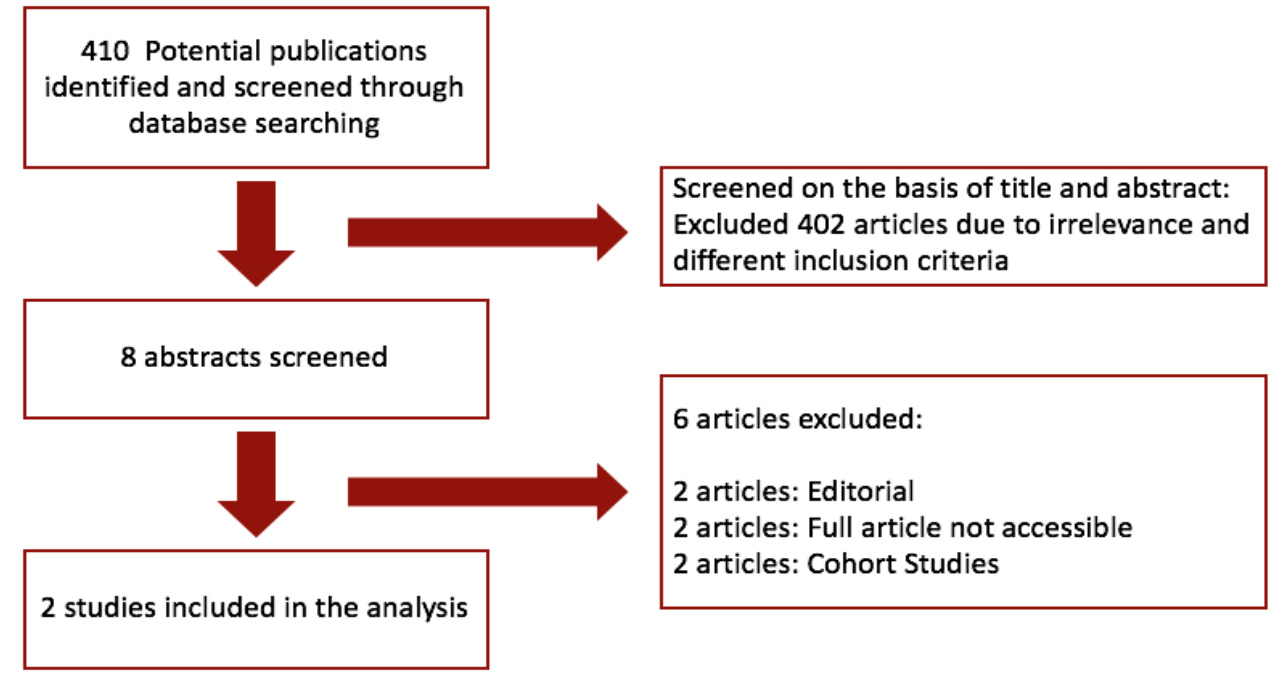

Figure 1: PRISMA flow diagram of study screening and selection.

diovascular mortality among adult pregnant patients with peripartum cardiomyopathy.

\section{Methodology}

\section{Selection criteria}

Studies were included in this systematic review and meta-analysis if they satisfied the following inclusion criteria: 1) Randomized Controlled Trials; 2) Adult pregnant patients who developed peripartum cardiomyopathy; and 3) Reported data on improvement in left ventricular ejection fraction and cardiovascular mortality. Studies among pediatric patients, patients with concomitant cardiac pathologies, patients with prior left or right ventricular dysfunction not due to peripartum cardiomyopathy, and those with significant pulmonary, hepatic and renal impairment will not be included.

\section{Literature search}

The three authors of this review independently performed a systematic computer search in the Pubmed, Science Direct, Medline, Clinical Trials, and Cochrane Central Register of Controlled Trials databases for eligible studies (from June to December 2018) using a combination of the following search terms: "Peripartum Cardiomyopathy", "Bromocriptine", "Left Ventricular Ejection Fraction", and "Cardiovascular Mortality". No language, data, or publication restrictions will be imposed.

\section{Data collection and quality assessment}

The identified studies were evaluated independently by the authors to determine their relevance for full text retrieval. The eligibility of the studies was then assessed by two independent reviewers (LKE and MCV) according to the specified inclusion criteria. Each RCT study that fulfilled the inclusion criteria was assessed of methodological quality using the Cochrane Risk of Bias Tool for Randomized Clinical Trials. Reasons for exclusion were document- ed. Disagreements were resolved by discussion with a third author. The author/s, year published, study design, population characteristics, sample size, interventions, and outcomes were extracted from each study. Disagreements were again resolved by discussion with the third author.

\section{Data analysis}

Meta-analysis was conducted using the Inverse variance random-effects model for continuous outcomes to generate mean differences, $95 \%$ confidence intervals (Cls), and forest plots. For dichotomous outcomes, we used the Mantel-Haenzel random-effects model to generate risk ratios, $95 \%$ confidence intervals ( $\mathrm{Cls}$ ), and forest plots. Heterogeneity was assessed through the chi square and $\mathrm{I}^{2}$ test. All statistical analyses were carried out using Review Manager (RevMan) version 5.3 (The Nordic Cochrane Centre, The Cochrane Collaboration, Copenhagen).

\section{Results}

\section{Output of literature search}

Our systematic literature search (Figure 1) yielded a total of 5 studies. Two studies were prospective cohort studies and the full article of 1 study was not retrievable. We therefore included 2 randomized controlled trials involving 116 patients with peripartum cardiomyopathy for inclusion in this review.

\section{Description of included studies}

Table 1 summarizes the characteristics and details of the included studies. Both studies are single center randomized controlled trials. Both studies were conducted in different tertiary hospitals in Africa. The mean age of the patients included was $27.7 \pm 5.7$ years old. Majority of the patients included were in NYHA functional class III or IV. Most of the patients developed heart failure manifesting as acute dyspnea during the first postpartum month. The baseline LVEF 
Table 1: Characteristics of studies included in the meta-analysis.

\begin{tabular}{|c|c|c|c|c|}
\hline $\begin{array}{l}\text { Study Title, Author, } \\
\text { and Year of } \\
\text { Publication }\end{array}$ & $\begin{array}{l}\text { Population } \\
\text { and } \\
\text { Study Design }\end{array}$ & Intervention & Outcomes Measured & $\begin{array}{l}\text { Follow-up } \\
\text { Duration }\end{array}$ \\
\hline $\begin{array}{l}\text { Evaluation of } \\
\text { Bromocriptine in the } \\
\text { treatment of acute } \\
\text { severe peripartum } \\
\text { cardiomyopathy } \\
\text { Sliwa, et al. [16] }\end{array}$ & $\begin{array}{l}\text { Total N = } \mathbf{2 0} \text { patients } \\
\text { Mean Age: } \mathbf{2 6} \pm \mathbf{8} \\
\text { NYHA fC II: } \mathbf{5 0 \%} \\
\text { NYHA fC III/IV: } \mathbf{5 0 \%} \\
\text { Baseline LVEF (\%): } 27 \\
\pm 7.9 \\
\text { Randomized Controlled } \\
\text { Trial }\end{array}$ & 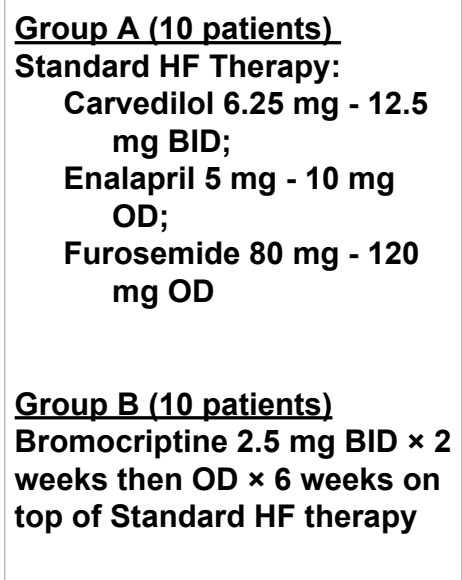 & $\begin{array}{ll}\text { - } & \text { Cardiovascular } \\
\text { Mortality } \\
\text { - }\end{array}$ & - 6 months \\
\hline $\begin{array}{l}\text { Bromocriptine } \\
\text { in management } \\
\text { of peripartum } \\
\text { cardiomyopathy: } \\
\text { A randomized study } \\
\text { on } 96 \text { women in } \\
\text { Burkina Faso. }\end{array}$ & $\begin{array}{l}\text { Total N = } 96 \text { patients } \\
\text { Mean Age: } 29.4 \pm 3.4 \\
\text { NYHA fc III: } 28.12 \% \\
\text { NYHA fc IV: } \mathbf{7 1 . 8 8 \%}\end{array}$ & $\begin{array}{l}\text { Group A (48 patients): } \\
\text { Standard HF therapy: } \\
\text { Captopril } 6.25 \mathrm{mg}-25 \mathrm{mg} \\
\text { OD } \\
\text { Furosemide } 80 \mathrm{mg} \text { OD }\end{array}$ & $\begin{array}{l}\text { - } \begin{array}{l}\text { Cardiovascular } \\
\text { Mortality }\end{array} \\
\text { - } \begin{array}{l}\text { Echocardiographic } \\
\text { parameters: }\end{array} \\
\text { LVEDD, LVESD, TAPSE } \\
\text { and LVEF } \\
\text { - Change in dyspnea }\end{array}$ & $\begin{array}{l}\text { - } 2 \text { weeks } \\
\text { - } 1 \text { month } \\
\text { - } 3 \text { months } \\
\text { - } 6 \text { months } \\
\text { - } 12 \text { months }\end{array}$ \\
\hline
\end{tabular}

HF: Heart Failure; LVEF: Left Ventricular Ejection Fraction; NYHA: New York Heart Functional Class; LVEDD: Left Ventricular End Diastolic Diameter;

LVESD: Left Ventricular End Diastolic Diameter; TAPSE: Tricuspid Annular Plane Systolic Excursion.

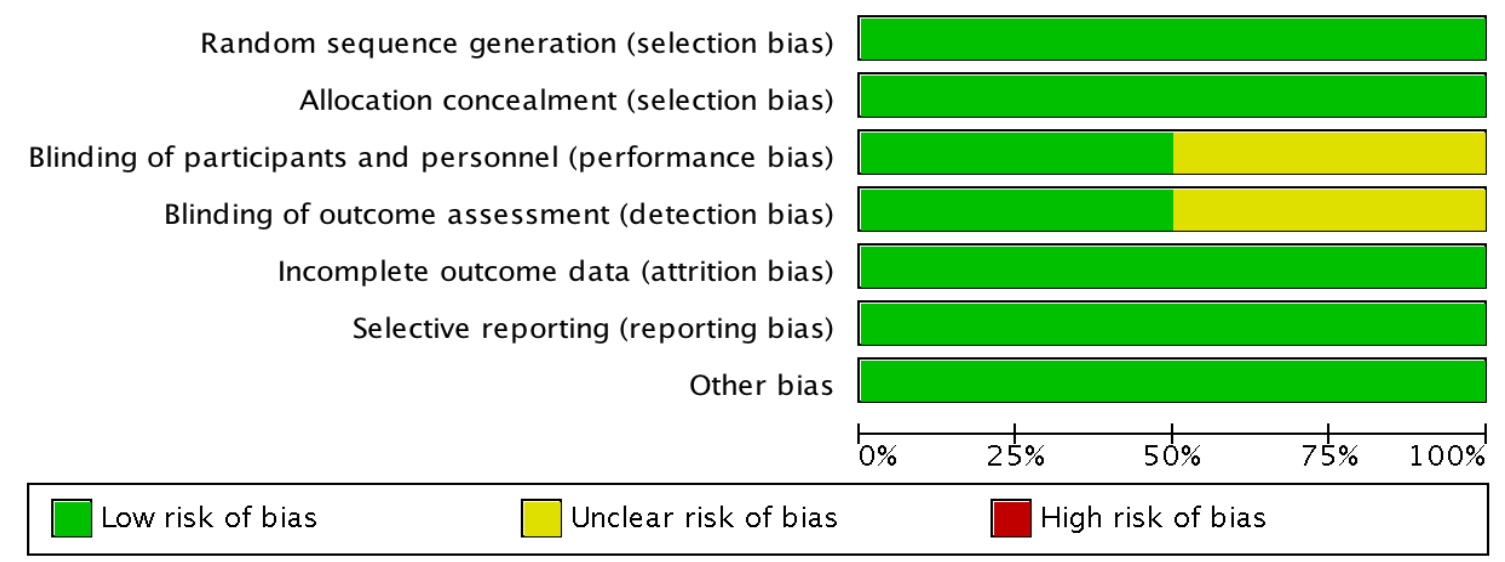

Figure 2A: Cochrane risk of bias assessment tool.

measured by transthoracic $2 d$-echo was $27 \% \pm 7.9$ and $36.4 \% \pm 5.5$ in the studies by Sliwa, et al. and Yameogo, et al. respectively. Both studies utilized standard heart failure regimen for the placebo group and added Bromocriptine to standard heart failure regimen in the experimental group. The outcomes measured cardiovascular mortality, echocardiographic parameters including improvement in left ventricular ejection fraction, and change in NYHA functional status.

\section{Quality assessment of included studies}

We have included two good quality studies in this 
study (Figure 2A and Figure 2B). Both studies were randomized controlled trials except that they did not specify blinding of the personnel and outcome assessors. Both studies reported completed data and there were no drop-outs.

\section{Results on the Outcomes of Interest}

\section{Changes in left ventricular ejection fraction (LVEF)}

The analysis of the 2 studies (Figure 3 ) showed that the addition of Bromocriptine to standard heart failure therapy improved the left ventricular ejection fraction by a mean difference of $15.14 \%$ [95\% $\mathrm{Cl} 6.53$ to 23.75 , $p=0.0006]$ after 6 months of treatment. There was a

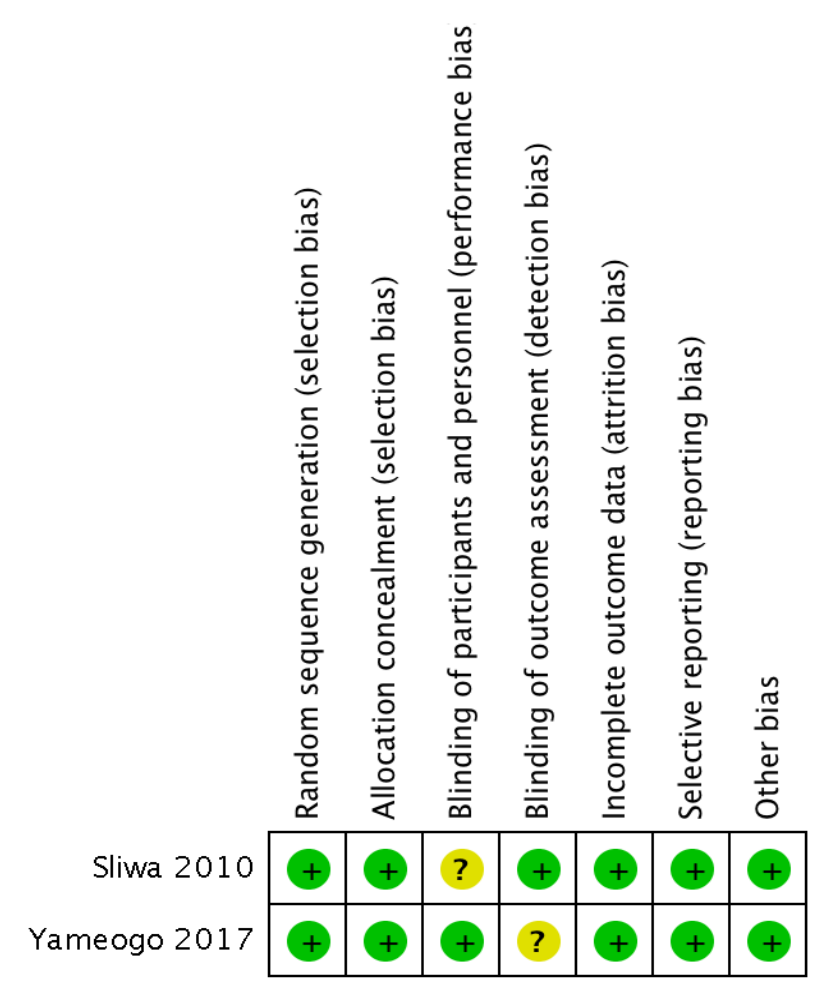

Figure 2B: Cochrane risk of bias assessment summary. moderate degree of heterogeneity with an $\mathrm{I}^{2}$ of $57 \%$.

\section{Cardiovascular mortality at 6-months follow-up}

The pooled risk ratio from the analysis of the 2 studies (Figure 4) showed that those who received Bromocriptine on top of standard heart failure therapy is associated with a lower cardiovascular mortality $(16 \%$ for Bromocriptine + standard HF therapy versus $31 \%$ for standard HF therapy) [RR 0.51, (95\% $\mathrm{Cl} 0.25$ to 1.06$), \mathrm{p}$ $=0.07]$.

\section{Discussion}

Despite advances in understanding the pathophysiology of PPCM, studies testing the disease-specific management beyond the standard therapy for heart failure in this condition are scarce. The nursing hormone prolactin and specifically its cleaved $16 \mathrm{kDa}$ form is considered to play a key role in the pathophysiology of PPCM. Most of the reports on clinical outcomes are limited to single center studies, case series, and retrospective studies with small sample size and short duration of follow-up.

Our meta-analysis confirms the hypothesis that Bromocriptine may be beneficial among patients with PPCM. Our study has showed that the addition of Bromocriptine to standard HF therapy improves the left ventricular ejection fraction greater (mean difference $15.14 \%, p=0.0006$ ) at 6 -months follow-up compared to standard HF therapy alone. These results confirm and strengthened the findings of both studies by Sliwa, et al. and Yameogo, et al. The greater recovery in LVEF has also been observed in a prospective cohort study of 115 patients in Germany by Haghikia, et al. [7] and among 51 patients by Marquis-Gravel, et al. [18] in 2015. In the study of Yameogo, et al. there was almost complete recovery of the LVEF at 12-months follow-up in the Bromocriptine treated group. In addition to LVEF recovery, there was also an observed

\begin{tabular}{|c|c|c|c|c|c|c|c|c|c|c|}
\hline \multirow{3}{*}{$\begin{array}{l}\text { Study or Subgroup } \\
\text { Sliwa } 2010 \\
\text { Yameogo } 2017\end{array}$} & \multicolumn{3}{|c|}{ Bromocriptine + Standard } & \multicolumn{3}{|c|}{ Standard } & Weight & $\begin{array}{l}\text { Mean Difference } \\
\text { IV, Random, } 95 \% \mathrm{CI}\end{array}$ & \multicolumn{2}{|c|}{$\begin{array}{c}\text { Mean Difference } \\
\text { IV, Random, } 95 \% \mathrm{Cl}\end{array}$} \\
\hline & 30.8 & 13.66 & 10 & 9.1 & 13.37 & 10 & $31.0 \%$ & $21.70[9.85,33.55]$ & & $-\square$ \\
\hline & 13.5 & 5.89 & 48 & 1.3 & 8.34 & 48 & $69.0 \%$ & $12.20[9.31,15.09]$ & & $r$ \\
\hline Total $(95 \% \mathrm{Cl})$ & & & 58 & & & 58 & $100.0 \%$ & $15.14[6.53,23.75]$ & & \\
\hline \multicolumn{9}{|c|}{$\begin{array}{l}\text { Heterogeneity: } \mathrm{Tau}^{2}=25.77 ; \mathrm{Chi}^{2}=2.33, \mathrm{df}=1(\mathrm{P}=0.13) ;\left.\right|^{2}=57 \% \\
\text { Test for overall effect: } Z=3.45(P=0.0006)\end{array}$} & $\begin{array}{lll}1 & 1 \\
-50 & -25 & 0 \\
\text { Favours Standard }\end{array}$ & $\begin{array}{c}11 \\
25 \\
\text { Favours Brc }\end{array}$ \\
\hline
\end{tabular}

Figure 3: Forest plot showing the mean difference between LVEF at 6 months in the Bromocriptine + Standard HF therapy and standard HF therapy groups.

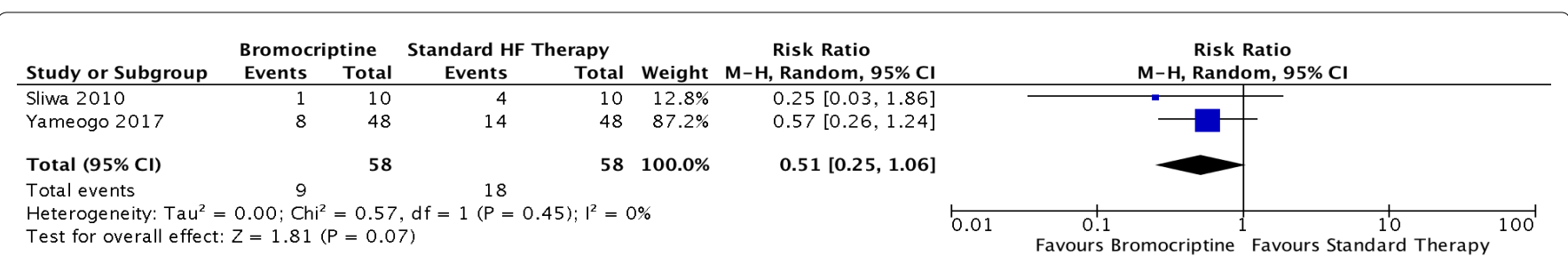

Figure 4: Forest plot showing the mean difference between LVEF at 6 months in the Bromocriptine + Standard HF therapy and standard HF therapy groups. 
greater recovery of NYHA functional class among those PPCM patients treated with Bromocriptine at 6-months follow-up. Most of the patients improved and recovered to NYHA functional class I from class III - IV. Furthermore, those on Bromocriptine did not need advanced heart failure therapy such as left ventricular assist device. A systematic review of prospective studies comprising of 445 patients by Asad, et al. [19] in 2018 demonstrated the same results where LVEF recovered at the time of follow up in $50 \%$ of the patients included. Cardiovascular mortality was also lower among those treated with Bromocriptine. These findings may support the beneficial cardioprotective effects of Bromocriptine resulting from the elimination of the detrimental $16-\mathrm{kDa}$ prolactin which was postulated to have harmful effects on the heart and the vasculature $[9-12,13,20]$.

Cardiovascular deaths were reported in both studies $[16,17]$. There were more cardiovascular deaths in the standard heart failure therapy group and the addition of Bromocriptine was associated with a trend towards lower cardiovascular mortality (16\% for Bromocriptine + standard HF therapy versus $31 \%$ for standard HF therapy) [RR 0.51, (95\% Cl 0.25 to 1.06), $p=0.07$ ]. Interestingly, cardiovascular deaths occurred only during the first 6 months from the time of diagnosis and no deaths were recorded beyond 6 months. This suggests that the critical period of intense heart failure surveillance and management should be within this time period. The most common cause of cardiovascular death among these patients was advanced heart failure or sudden cardiac death occurring within 3 months.

It is known that the postpartum period is associated with an increased risk of thrombosis and myocardial infarction, probably because of changes in coagulation that may have evolved as a protection from bleeding caused by child birth [21]. Concerns have been raised about Bromocriptine's potential risk for cerebral and cardiovascular complications, as emphasized in some case reports describing stroke [22], coronary artery thrombosis [23], and coronary artery vasospasm [24]. Since Bromocriptine is known to be pro-thrombotic, adverse effects such as stroke or thrombotic events were monitored. In the study by Sliwa, et al. [16], there were no reports of any thromboembolic events. However, there were a few reports of stroke and pulmonary embolism in the study by Yameogo, et al. [17] but it was not statistically significant between the two groups. Patients who have a severely depressed EF at baseline in both groups were anticoagulated during the third trimester due to the increased risk of thromboembolic events seen among pregnant patients. Bromocriptine did not increase their risk for such events. In addition, Bromocriptine did not increase the risk of abortion or congenital malformations among 1400 pregnant patients who took it during the first trimester [25].
The strength of this meta-analysis is that the included studies were randomized controlled trials. Previous reports have analyzed cohort studies. The primary outcome reported was a measurement of LVEF at 6 months which is standard for both the included studies.

Our study has few limitations worth mentioning. First, despite observing significant improvement of LVEF at 6-months follow-up, the results should be interpreted with caution since we observed a moderate degree of heterogeneity. The major cause of this heterogeneity is the small sample size included in both studies. There was a total of 116 patients only included for analysis. Second, the class of medications and dose of heart failure regimen were different for both studies. One study utilized an ace-inhibitor + beta blocker + diuretic regimen while the other study used an ace-inhibitor + diuretic regimen only. Lastly, the optimal dose of Bromocriptine used in both studies were similar at $2.5 \mathrm{mg}$ twice a day but the duration was different between the two studies included ( 8 weeks vs. 4 weeks).

With the evidence presented in this meta-analysis, we therefore propose the conduct of larger clinical trials to increase the evidence's strength on the use of Bromocriptine in peripartum cardiomyopathy patients.

\section{Conclusion}

Our study has demonstrated that addition of Bromocriptine to standard heart failure therapy may improve the left ventricular ejection fraction recovery of patients with peripartum cardiomyopathy better than standard heart failure therapy alone.

\section{Acknowledgement}

I cannot express enough thanks to my co-authors and consultant mentors for their continued support and guidance in the completion of this research. Also this would not have been easily accomplished without the support of the Division of Cardiovascular Medicine and the Department of Medicine.

\section{Ethical compliance with human/animal study}

There are no humans or animals included in this study.

\section{Informed consent}

No informed consent was needed for this study since there were no involvement of any patient or participant.

\section{Disclosure of Conflict of Interest}

No competing interests exist between the authors and any institution or pharmaceutical company.

\section{Funding Sources}

This study is funded by the primary author. No other source of funds were provided in the completion of this study. 


\section{Authors contribution}

All authors have directly participated in this study. DLV and MCEV were involved in the planning and analysis of results of this study, LKE gathered the necessary data needed for analysis, and JCA read, supervised, and approved the final version submitted.

\section{Institutional review board}

This paper has been registered with the Research and Grants Office of the University of the Philippines Research Ethical Board. The hospital affiliation: Division of Cardiovascular Medicine, Department of Medicine, University of the Philippines - Philippine General Hospital is fully aware of this submission.

\section{Data availability statement}

The data used to support the findings of this study are available from the corresponding author upon request.

\section{References}

1. Sliwa K, Fett J, Elkayam U (2006) Peripartum cardiomyopathy. Lancet 368: 687-693.

2. Hilfiker-Kleiner D, Sliwa K (2014) Pathophysiology and epidemiology of peripartum cardiomyopathy. Nat Rev Cardiol 11: 364-370.

3. Sliwa K, Hilfiker-Kleiner D, Petrie MC, Mebazaa A, Pieske B, et al. (2010) Current state of knowledge on aetiology, diagnosis, management, and therapy of peripartum cardiomyopathy: A position statement from the Heart Failure Association of the European Society of Cardiology Working Group on peripartum cardiomyopathy. Eur J Heart Fail 12: 767-778.

4. Fett JD, Christie LG, Carraway RD, Murphy JG (2005) Fiveyear prospective study of the incidence and prognosis of peripartum cardiomyopathy at a single institution. Mayo Clin Proc 80: 1602-1606.

5. Amos AM, Jaber WA, Russell SD (2006) Improved outcomes in peripartum cardiomyopathy with contemporary. Am Heart J 152: 509-513.

6. Blauwet LA, Libhaber E, Forster O, Tibazarwa K, Mebazaa A, et al. (2013) Predictors of outcome in 176 South African patients with peripartum cardiomyopathy. Heart 99: 308313.

7. Haghikia A, Podewski E, Libhaber E, Labidi S, Fischer D, et al. (2013) Phenotyping and outcome on contemporary management in a German cohort of patients with peripartum cardiomyopathy. Basic Res Cardiol 108: 366.

8. Sliwa K, Forster O, Libhaber E, Fett JD, Sundstrom JB, et al. (2006) Peripartum cardiomyopathy: Inflammatory markers as predictors of outcome in 100 prospectively studied patients. Eur Heart J 27: 441-446.

9. Halkein J, Tabruyn SP, Ricke-Hoch M, Haghikia A, Nguyen NQ, et al. (2013) MicroRNA-146a is a therapeutic target and bio-marker for peripartum cardiomyopathy. J Clin Invest 123: 2143-2154.
10. Hilfiker-Kleiner D, Kaminski K, Podewski E, Bonda T, Schaefer A, et al. (2007) A cathepsin D-cleaved $16 \mathrm{kDa}$ form of prolactin mediates postpartum cardiomyopathy. Cell 128: 589-600.

11. Patten IS, Rana S, Shahul S, Rowe GC, Jang C, et al. (2012) Cardiac angiogenic imbalance leads to peripartum cardiomyopathy. Nature 485: 333-338.

12. Ricke-Hoch M, Bultmann I, Stapel B, Condorelli G, Rinas $U$, et al. (2014) Opposing roles of Akt and STAT3 in the protection of the maternal heart from peripartum stress. Cardiovasc Res 101: 587-596.

13. Hilfiker-Kleiner D, Meyer GP, Schieffer E, Goldmann B, Podewski E, et al. (2007) Recovery from postpartum cardiomyopathy in 2 patients by blocking prolactin release with bromocriptine. J Am Coll Cardiol 50: 2354-2355.

14. Jahns BG, Stein W, Hilfiker-Kleiner D, Pieske B, Emons G (2008) Peripartum cardiomyopathy--A new treatment option by inhibition of prolactin secretion. Am J Obstet Gynecol 199: e5-e6.

15. Mejia-Rodriguez O, Herrera-Abarca JE, Ceballos-Reyes G, Avila-Diaz M, Prado-Uribe C, et al. (2013) Cardiovascular and renal effects of bromocriptine in diabetic patients with stage 4 chronic kidney disease. Biomed Res Int 2013: 104059.

16. Sliwa K, Blauwet L, Tibazarwa K, Libhaber E, Smedema $\mathrm{JP}$, et al. (2010) Evaluation of bromocriptine in the treatment of acute severe peripartum cardiomyopathy: A proofof-concept pilot study. Circulation 121: 1465-1473.

17. Yaméogo NV, Kagambèga LJ, Seghda A, Owona A, Kaboré O, et al. (2017) Bromocriptine in management of peripartum cardiomyopathy: A randomized study on 96 women in Burkina Faso. J Cardiol Clin Res 5: 1098.

18. Marquis-Gravel G, Desplantie O, Avram R, Tremblay-Gravel M, Tran D, et al. (2015) Bromocriptine for the treatment of peripartum cardiomyopathy: A case control study across academic centers in Québec. Can J Cardiol 31: S293.

19. Asad ZUA, Maiwand M, Farah F, Dasari TW (2018) Peripartum cardiomyopathy: A systematic review of the literature. Clin Cardiol 41: 693-697.

20. Hilfiker-Kleiner D, Sliwa K, Drexler H (2008) Peripartum cardiomyopathy: Recent insights in its pathophysiology. Trends Cardiovasc Med 18: 173-179.

21. James AH, Brancazio LR, Ortel TL (2005) Thrombosis, thrombophilia, and thromboprophylaxis in pregnancy. Clin Adv Hematol Oncol 3: 187-197.

22. Iffy L, Lindenthal J, McArdle JJ, Ganesh V (1996) Severe cerebral accidents postpartum in patients taking bromocriptine for milk suppression. Isr J Med Sci 32: 309-312.

23. Loewe C, Dragovic LJ (1998) Acute coronary artery thrombosis in a postpartum woman receiving bromocriptine. Am J Forensic Med Pathol 19: 258-260.

24. Hopp L, Weisse AB, Iffy L (1996) Acute myocardial infarction in a healthy mother using bromocriptine for milk suppression. Can J Cardiol 12: 415-418.

25. Turkalj I, Braun P, Krupp P (1982) Surveillance of bromocriptine in pregnancy. JAMA 247: 1589-1591. 